\title{
Study of 0D, 1D and 3D Zinc Oxide Morphologies by SEM and TEM
}

\author{
JE Morales-Mendoza ${ }^{1}$ and F Paraguay-Delgado ${ }^{1 *}$, E Lestarjet $^{1}$, D Lardizabal $^{1}$ and L de la Torre $Z^{1}$ \\ ${ }^{1 .}$ Centro de Investigación en Materiales Avanzados SC (CIMAV), Departamento de Física de Materiales, \\ Miguel de Cervantes No.120, Chihuahua, Chih., México. \\ * Corresponding author: Francisco.paraguay@cimav.edu.mx
}

Zinc oxide $(\mathrm{ZnO})$ is widely used semiconductor oxide. The size and morphology control are important to give specific properties to nanostructured materials. $\mathrm{ZnO}$ is interesting due to its optical and electrical properties, this material is useful for solar cells, gas sensing, photocatalytic and UV filter applications. In this study we will present three morphologies nanoparticles (0D), flakes (1D) and rods (3D). The ZnO at bulk level presents a good absorbance in the UV region, but by taking it to the nanometer scale this property is improve [1].

The synthesis of $\mathrm{ZnO}$ nanoparticles (0D) was obtained by the precipitation method (PM) through a reflux system. It is prepared a solution $(\mathrm{S} 1)$ of zinc acetate dihydrate $(1.316 \mathrm{~g})$ in ethanol $(80 \mathrm{ml})$. Then was made a second solution (S2) of sodium borohydride $(0.6 \mathrm{~g})$ in ethanol $(40 \mathrm{ml})$ adding it carefully to $\mathrm{S} 1$. After finish adding the $\mathrm{S} 2$, it was added $\mathrm{H}_{2} \mathrm{O}_{2}(7 \mathrm{ml}$ with $3 \%$ purity). The final solution (S3) was diluted adding $500 \mathrm{ml}$ boiling water and filtered by gravity. Finally, the resulting paste was dried by 5 hours at $80{ }^{\circ} \mathrm{C}$. The $\mathrm{ZnO}$ flakes (1D) and $\mathrm{ZnO}$ rods (3D) was synthesized by hydrothermal method (HM) which is one of the most used techniques. It was made a zinc acetate dihydrate $(1.09 \mathrm{~g})$ solution in water $(15 \mathrm{ml})$ for both morphologies and it was maintained at vigorous stirring, then was added potassium hydroxide; $0.85 \mathrm{~g}$ and $4.2 \mathrm{~g}$ for flakes and rods, respectively. After both the salts dissolves, ethanol $(15 \mathrm{ml})$ is added by dripping. The final solution was transferred to a teflon vial and was introduce inside autoclave flask. Then it was made heat treatment inside a conventional oven at $160{ }^{\circ} \mathrm{C}$ for 24 hours. Finally, the product obtained was washed and centrifugation with deionized water. Morphology and growth mechanisms were studied by SEM and TEM image techniques.

The morphology of $\mathrm{ZnO}$ nanoparticles with $0 \mathrm{D}$ are show in the figures $1 \mathrm{a}, 1 \mathrm{~d}$ and $1 \mathrm{~g}$ which are images acquired by SEM and TEM, the size of then are $8 \pm 2 \mathrm{~nm}$ with round shape, they are agglomerate. Particle with $1 \mathrm{D}$ are show in the figures $1 \mathrm{~b}, 1 \mathrm{e}$ and $1 \mathrm{~h}$, the size of them are diameter of $270 \pm 60 \mathrm{~nm}$ with thickness average of $47 \pm 7 \mathrm{~nm}$, the image at high magnification (Fig. $1 \mathrm{~h}$ ) show it crystallinity a d-space are $2.6 \AA$ which belongs to (100) direction. The 3D particles images are show in the figures $1 \mathrm{c}, 1 \mathrm{f}$ and 1i, they show elongated hexagonal prism rods with six faces pyramidal ending tip. The size measurement from the images are in length has as average of $8.3 \pm 2 \mu \mathrm{m}$ and $0.77 \pm 0.15 \mu \mathrm{m}$ diameter. Many methods have been used to obtained different morphologies $[2,3,4]$. In our case we focus in PM and HM techniques for synthesis repeatedly.

\section{References:}

[1] S Ghamsari et al, International Journal of Nanomedicine. 12 (2017).

[2] Y Liu et al, J. Phys. Chem. B 110 (2006), p. 20263.

[3] Sh.A Mansour et al, Spectrochimica Acta Part A: Molecular and Biomolecular Spectroscopy 148 (2015), p. 362.

[4] M Kahouli et al, Superlattices and Microstructures 85 (2015), p. 7. 


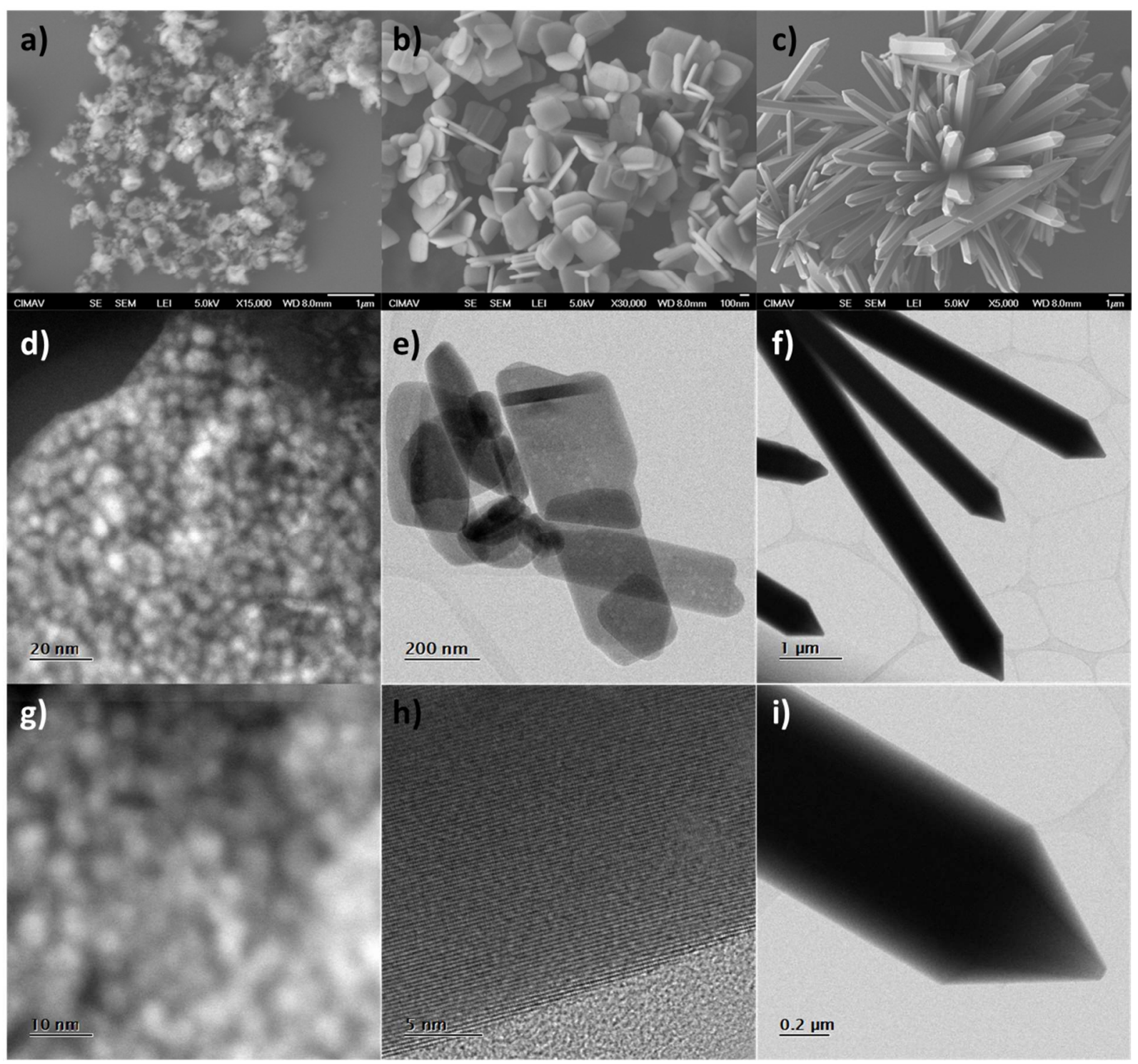

Figure 1. $\mathrm{ZnO}$ synthetized by $\mathrm{PM}$ a), d) and g). Then by $\mathrm{HM} \mathrm{b),} \mathrm{e),} \mathrm{h),} \mathrm{c),} \mathrm{f)} \mathrm{and} \mathrm{i).}$ 